\title{
Associations of Birth Defects with Adult Intellectual Performance, Disability and Mortality: Population-based Cohort Study
}

\author{
MARTHA G. EIDE, ROLV SKJÆRVEN, LORENTZ M. IRGENS, TOR BJERKEDAL, AND NINA ØYEN
}

Department of Public Health and Primary Health Care [M.G.E., R.S., L.M.I., N.Ø.], The Medical Birth Registry of Norway [R.S., L.M.I., N.Ø.], University of Bergen, N-5018 Bergen, Norway; Division of Military Research and Development [T.B.], Joint Norwegian Medical

Services, N-0753 Oslo, Norway

\begin{abstract}
Infants born with birth defects have poorer outcomes in terms of mortality and disability, but the long-term intellectual outcome in children with birth defects is generally unknown. We assessed the long-term associations of various birth defects with mortality and disability, and evaluated whether high mortality and disability were reflected in impaired intellectual performance at age 18. In this nationwide cohort study, records of 9,186 males with and 384,384 without birth defects, registered in the Medical Birth Registry of Norway (1967-1979) were linked to the National Conscript Service (1984-1999). Mortality and disability before military draft, and intelligence test score at conscription were the main outcome measures. Males with birth defects had a relative risk for disability of 6.0 compared with males without defects. Disability was low within categories of birth defects associated with low mortality, and high within defect categories associated with high mortality. The relative risk for not being drafted was highest if maternal educational level was low. Heart defects and cleft palate were the only subgroups in which intellectual performance was lower after adjustment for maternal education, maternal age, marital status and birth order. In particular, intellectual performance was not impaired among those with multiple compared with single defects. We conclude that for the majority of birth defect categories in the present birth cohort, our hypothesis that intellectual performance would be impaired was not confirmed. Thus, there seems to be little reason to fear an adverse intellectual outcome in non-disabled surviving infants with birth defects. (Pediatr Res 59: 848-853, 2006)
\end{abstract}

$I^{\prime}$ nfants with birth defects have increased peri-natal and post-natal mortality $(1,2)$, lower birth weight (3), as well as lower survival to age $20 \mathrm{y}$; dependent on type of defect $(1,4)$. Furthermore, infants with birth defects are at increased risk of childhood morbidity and disability $(2,5)$, including reproductive failure (4), also depending on the type of birth defect.

Disablement may be the result of physical or intellectual impairment. In modern societies, intellectual function is an important predictor of long-term health outcomes (6), as well as later employment history and social class (7-9). Studies

Received August 2, 2005; accepted January 19, 2006.

Correspondence: Martha Gunn Eide, M.D., Ph.D., Section for Epidemiology and Medical Statistics, Department of Public Health and Primary Health Care, University of Bergen, Kalfarveien 31, N-5018 Bergen, Norway; e-mail: martha.eide@mfr.uib.no

This work was funded by the Norwegian Research Council grant no. 129248/330, and supported by a grant from the Western Norway Regional Health Authority.

DOI: $10.1203 / 01$.pdr.0000219172.16638.f9 dealing with the influence of birth defects on adult disability are scarce. Furthermore, the extent to which birth defects may affect intellectual function is largely unknown except in a few specific types of birth defects $(10-12)$. No population-based follow-up study has investigated variation in disability and intellectual performance according to the presence of various birth defects.

In Norway, since 1967, medical data on all births (including stillbirths) from $16 \mathrm{wk}$ of gestation are recorded by the Medical Birth Registry of Norway (13). Data on intellectual performance are routinely recorded by the National Conscripts Service in all Norwegian men at the age of 18 y $(14,15)$. Data on disability status are registered in the National Health Insurance Office. Initially, our aims were to assess the longterm associations of various birth defects on mortality and disability until age $18 \mathrm{y}$, and next, to explore whether intellectual performance at conscription would be impaired in sub-groups of birth defects with high mortality and disability. Furthermore, we wanted to investigate whether intellectual performance would be impaired in some birth defects more than others, and whether multiple defects were at a particular disadvantage.

\section{METHODS}

Study population. From 1967 to 1979, 393,570 singleton male live births were registered in the Medical Birth Registry providing data on birth defects and birth order (including stillbirths), as well as maternal marital status and age when giving birth. All Norwegian men are required to register with the draft board at age $18 \mathrm{y}$ for physical and mental examinations. Only those registered in the National Health Insurance Office (NHIO) as being permanent disabled physically or mentally are exempted. All Norwegian residents are compulsory insured in the NHIO, which provides a benefit to any individual with a disability involving significant expenses. The NHIO confirms and records diagnoses based on medical examinations by physicians and specialists. We defined disability as not being drafted and registered in the NHIO with at least one diagnosis based on the International Classification of Diseases. By the national identification number, data from the Medical Birth Registry were linked with data on disability status from the National Health Insurance Office 1967-1997, on intellectual performance recorded by the

Abbreviations: ICD-8, International Classification of Diseases $8^{\text {th }}$ Revision; NHIO, National Health Insurance Office; OR, odds ratio; RR, relative risk 
National Conscripts Service 1984-1999, and data on mortality, as well as maternal educational level (completed years), from Statistics Norway 19671998.

Births were divided into those with a registered birth defect $(9,186 ; 2.4 \%)$ and those without such a defect $(384,384 ; 97.6 \%)$. Of the total birth cohort, $8,383(2.1 \% ; 1,160$ with and 7,223 without a birth defect, respectively) died before military draft, 3,788 (1.0\%) emigrated, 5,692 (1.4\%) were not drafted due to disability, and another $24,355(6.2 \%)$ were untraceable (15). Draft board medical data were obtained for 351,352 men (15). Mean age at conscription was 18.7 y (SD 1.0 and 0.7 for those with and without birth defects, respectively), with $99.7 \%$ aged 18 y or more. Analyses of intellectual performance were restricted to conscripts with data on intelligence testing and maternal educational level. This excluded 33,591 men, leaving 6,023 in the study cohort with a birth defect $(65.6 \%$ of all males born with a birth defect), and 311,738 without a birth defect $(81.1 \%$ of those born without a birth defect) for analysis (Table 1). Data on maternal age, marital status, and birth order were complete for the study cohort.

Classification of birth defects. During the initial hospitalization (usually 5-7 d), every newborn undergoes a medical examination (including screening blood tests as well as possible additional diagnostic procedures) by a physician, usually a pediatrician. During the study period, the Medical Birth Registry has recorded birth defects that were diagnosed based on these examinations. Apart from the notification form, which is compulsory in every birth, no additional source of ascertainment was available. We defined 26 categories of birth defects on the basis of the International Classification of Diseases, Eighth Revision (ICD-8), consistent with previous studies $(1,4)$. For most affected infants, only one single birth defect diagnosis was reported. When spina bifida was present with anencephaly, only anencephaly was counted, and when spina bifida was present with hydrocephalus, only spina bifida was counted. All other cases with multiple birth defect diagnoses were combined in one separate category. We defined separate categories for clubfoot and hip dysplasias, which were excluded from the category of limb defects. Also, we defined separate categories for isolated cleft lip and cleft palate, and for combined cleft lip and palate. Finally, Down's syndrome was separated from other recognized syndromes. The categories were mutually exclusive, 25 containing isolated defects and 1 containing multiple defects.

Intelligence testing. General intellectual performance was measured by a 53 min validated group intelligence test, which was developed in 1953 for the Norwegian draft board, and revised in 1962. The test included time-limited sub-tests covering three categories of items: verbal analogues, number series (calculation) and geometrical figures (an abbreviated version of Raven's Progressive Matrices) (16). Each sub-test was organized by increasing difficulty. The test questionnaire comprised a total of 120 questions. All conscripts received standard instructions before the time-limited tests. The test is highly correlated with the Wechsler Adult Intelligence Scale $(r=0.73)(14,16,17)$. The result is presented as standard nine ("stanine") scores; i.e., single-digit standard scores (with values from 1 to 9) based on a normal distribution, in which the mean is 5.0 and the SD is 1.96. A low score was defined as equal or less than 3 , corresponding to the $16^{\text {th }}$ percentile of the stanine distribution. In the text, stanine score is termed intelligence test score.

Statistics. Mortality was calculated as the proportion of infants within each birth defect category who died before military draft among those born alive with such a defect. Likewise, disability was estimated as the proportion of infants within each birth defect category who were registered as disabled (and not drafted) among those born alive with such a defect. Disability was calculated among survivors (i.e., excluding those who were dead before military draft). Relative risks (RR) with 95\% confidence intervals (CI) for mortality, disability, and for not being drafted (due to any reason) were calculated using $2 \times 2$ tables. Intelligence test score was analyzed using analysis of variance (crude and adjusted analyses). In these models, all independent variables were treated as categorical. Maternal age was categorized into five groups (19 y or less, 20-24 y 25-29 y, $30-34 \mathrm{y}$, and $35 \mathrm{y}$ or more), marital status as married or unmarried, and birth order into 1 , and 2 or more. Maternal educational level was classified into low ( $<10$ y), medium (11-14 y), or high $(>14$ y). Odds ratios $(O R)$ for a low score were calculated using logistic regression analysis. All tests were two-sided, and $p<0.05$ was chosen as the level of statistical significance. SPSS software (version 12.0.1, SPSS, Chicago, IL) was used for statistical analyses.

Ethical approval. The study has been cleared by the Regional Committee for Medical Research Ethics, and approved by the Norwegian Board of Health and the Norwegian Data Inspectorate.

\section{RESULTS}

Among 393,570 singleton live infant males born during 1967-1979, altogether 385,187 (97.9\%) survived until 1999. The RR for mortality before military draft for males with birth

Table 1. Male live births in Norway 1967-1979 with proportions of birth defects, according to follow-up status from birth through military conscription 1984-1999

\begin{tabular}{|c|c|c|c|c|c|c|c|}
\hline Follow-up status & $\begin{array}{c}\text { Total } \\
\text { live births* } \\
n\end{array}$ & $\begin{array}{l}\text { Dead before } \\
\text { military draft } \\
n(\%) \|\end{array}$ & $\begin{array}{c}\text { Disabled and } \\
\text { not drafted } \\
n(\%)\end{array}$ & $\begin{array}{c}\text { Drafted } \dagger \\
n(\%)\end{array}$ & $\begin{array}{c}\text { Study cohort } \\
n(\%)\end{array}$ & $\begin{array}{l}\text { RR mortality } \S \\
\quad(95 \% \mathrm{CI})\end{array}$ & $\begin{array}{l}\text { RR disability } \\
\quad(95 \% \mathrm{CI})\end{array}$ \\
\hline \multicolumn{8}{|l|}{ Birth defect categoryII } \\
\hline Hydrocephalus & 59 & $29(49.2)$ & $5(16.7)$ & $23(39.0)$ & $21(35.6)$ & $26.2(20.2$ to 33.9$)$ & 12.5 (5.6 to 27.7$)$ \\
\hline Heart & 445 & $210(47.2)$ & $23(9.8)$ & $195(43.8)$ & $166(37.3)$ & $25.1(22.7$ to 27.8$)$ & $7.3(5.0$ to 10.8$)$ \\
\hline Cleft lip & 250 & $6(2.4)$ & $3(1.2)$ & $227(90.8)$ & $202(80.8)$ & $1.3(0.6$ to 2.8$)$ & $0.9(0.3$ to 2.8$)$ \\
\hline Abdominal wall & 206 & $72(35.0)$ & $7(5.2)$ & $118(57.3)$ & $110(53.4)$ & $18.6(15.4$ to 22.4$)$ & $3.9(1.9$ to 8.0$)$ \\
\hline Genitalia & 2466 & $48(1.9)$ & $67(2.8)$ & $2165(87.8)$ & $1955(79.3)$ & $1.0(0.8$ to 1.4$)$ & 2.1 (1.6 to 2.6$)$ \\
\hline Clubfoot & 2105 & $60(2.9)$ & $62(3.0)$ & $1795(85.3)$ & $1595(75.8)$ & $1.5(1.2$ to 1.9$)$ & $2.3(1.8$ to 2.9$)$ \\
\hline Limb defects & 869 & $48(5.5)$ & $49(6.0)$ & 709 (81.6) & $601(69.2)$ & $2.9(2.2$ to 3.9$)$ & $4.5(3.4$ to 5.9$)$ \\
\hline Hip & 344 & $11(3.2)$ & $9(2.7)$ & $299(86.9)$ & $274(79.7)$ & 1.7 (1.0 to 3.0$)$ & $2.0(1.1$ to 3.8$)$ \\
\hline Skin/hair/nail & 204 & $5(2.5)$ & $5(2.5)$ & $185(90.7)$ & $170(83.3)$ & $1.3(0.5$ to 3.1$)$ & $1.9(0.8$ to 4.5$)$ \\
\hline
\end{tabular}

* Not all categories of defects and follow-up status are listed, so numbers do not sum to totals shown.

$\dagger$ Among those drafted, data on intelligence test score or maternal educational level were missing for $n=451$ with birth defects, and for $n=33,140$ without birth defects.

$\ddagger$ Conscripts with complete data on birth characteristics, intelligence test score and maternal educational level.

$\S$ Relative risk.

$\|$ Percent of all live births in each birth defect category.

II Defects are defined according to the International Classification of Diseases, 8th Revision.

** Calculated among survivors (i.e., excluding those who were dead before military draft). 
defects was 6.7 (95\% CI: 6.3-7.1) compared with those without defects (Table 1). Further, RR for disability among males with any birth defect who survived until age 18 was 6.0 (5.5-6.5) compared with males without defects. The increased RR for mortality was significant for all categories of birth defects, except for cleft lip, genitalia, hip, and skin/hair/nail; whereas RR for disability was significantly increased for all categories, except for cleft lip and skin/hair/nail, as well as respiratory defects (the latter group had no disabled cases).

Figure 1 shows mortality and disability for the various birth defect categories, with details for 13 of the 26 categories listed in Table 1 . The disability among men at $18 \mathrm{y}$ was low within the categories of birth defects associated with low mortality, whereas the disability was high within birth defect categories associated with high mortality (Fig. 1). Thus, the birth defect categories seemed to appear in two clusters. However, for eye defects, the disability was relatively high despite low mortality, and for abdominal wall defects the disability was low despite a relatively high mortality.

For males with any birth defect, the RR for not being drafted (due to any reason) was 2.5 (2.4-2.6) compared with males with no birth defect. Stratified on maternal educational level, the RR for not being drafted among males with a birth defect compared with those with no defect was 2.9 (2.7-3.1), $2.4(2.3-2.5)$, and $2.2(2.0-2.5)$ for sons of mothers at the low, medium, and high level, respectively. Thus, there was an interaction between maternal education and infants with birth defects on the risk for not being drafted $(p<0.05)$.

Table 2 presents mean intelligence test score at conscription by birth defects stratified by potential confounding factors. Within each category, maternal age and educational level were positively associated with intelligence test score, whereas there was a negative association with birth order and being unmarried $(p<0.0005$ for all).

Overall, mean intelligence test score was 5.26 for conscripts with birth defects compared with 5.22 in the reference group

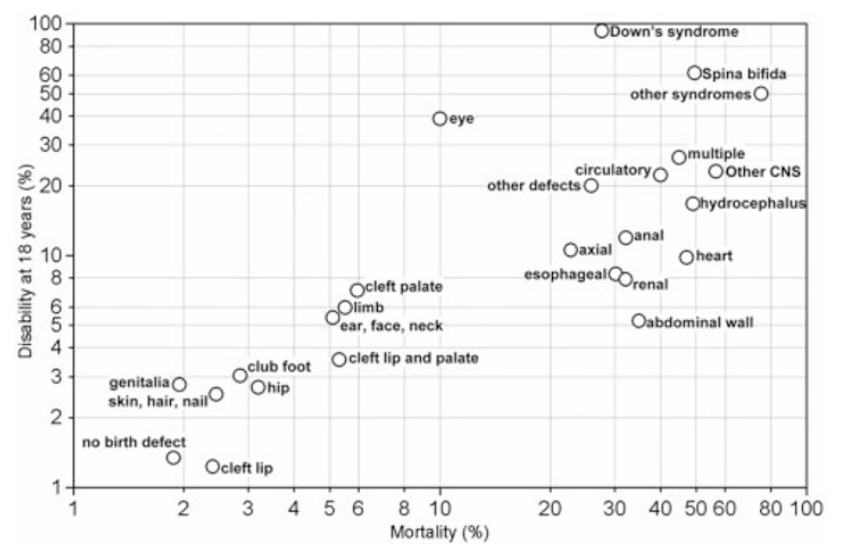

Figure 1. Mortality* and disability $\dagger$ among males born with birth defects according to category of defect; 393,570 male infants, Medical Birth Registry of Norway, 1967-1979, linked with Statistics Norway, 1967-1998, and the National Health Insurance Office, 1967-1997. Please note that both scales are logarithmic. * the proportion of infants within a birth defect category who were dead before military draft among those born alive with such a defect $\dagger$ the proportion of infants within a birth defect category who were registered as disabled and not drafted among those born alive with such a defect, calculated among survivors (i.e., excluding those who were dead before military draft). $(p=0.081)$. No significant differences in mean intelligence test scores were observed for most categories of birth defects when compared with those without defects (Fig. 2). Still, males born with heart defects, cleft palate, and combined cleft lip and palate had slightly lower scores than those without defects. Also, although not statistically significant, scores for males with hydrocephalus, syndromes other than Down's, and other defects were low. In crude analyses scores for males with clubfoot and genitalia-defects were significantly higher than for those without defects. However, in analyses adjusted for birth order, maternal education, maternal age, and marital status, only the differences for males with heart defects and cleft palate remained significant $(p=0.007$ and 0.045 , respectively) (Table 3). Further adjustment for year of birth did not change these results.

As seen in Fig. 2, there was no significant difference in mean intelligence test score for individuals with multiple defects compared with those with no defects (mean score 5.11 versus $5.22, p=0.5$ ). Also, there was no difference when comparing the score for males with multiple defects with the overall score for those who had one single birth defect (5.11 versus $5.26, p=0.2$; adjusted for maternal education, maternal age, marital status, and birth order) (Table 3). Within the heart defect category, the intelligence test score was not lower among those who had additional defects compared with those who had a single heart defect diagnosis (5.30 versus $4.90, p=$ 0.7). Similarly, within the cleft palate category, there was no significant difference in mean score when comparing males having cleft palate only with those having additional birth defects $(p=0.6)$. For completeness, Table 3 also includes similar comparisons for cleft lip $(p=0.07)$ and combined cleft lip and palate $(p=0.8)$.

In a post hoc analysis, birth defects (except for eye defects) were categorized according to the impression in Fig. 1 of two possible clusters; one with mortality $<10 \%$, and the other with mortality $>20 \%$. The first group (consisting of nine categories of birth defects) had significantly higher intelligence test score than the group with higher mortality (mean scores 5.26 versus 5.03, $p=0.002$ ). Within the group associated with high mortality $(>20 \%$, consisting of fifteen categories) we compared intelligence test score in birth defect categories associated with disability $\geq 20 \%$ (eight categories) against $<20 \%$ (seven categories); however, there was no significant difference ( $p=$ $0.8)$.

Overall, the unadjusted OR for low intelligence test score among conscripts with birth defects was 0.98 (95\% CI: 0.92 $1.05)$ compared with no defects. The OR was significantly increased only among 'other syndromes' (3.40; $1.08-10.71)$ and 'multiple defects' (1.60; 1.09-2.29).

\section{DISCUSSION}

Men with heart defects or cleft palate registered at birth had their intellectual performance adversely affected; whereas for the majority of birth defect categories, our results did not confirm the hypothesis that intelligence test score at conscription would be impaired. These findings are clinically signifi- 
Table 2. Mean intelligence test score (IQ) by birth characteristics among 317,761 male conscripts with and without birth defects. Medical Birth Registry of Norway, 1967-1979, linked with the National Conscripts Service, 1984-1999, and Statistics Norway, 1967-1998

\begin{tabular}{|c|c|c|c|c|c|}
\hline Birth characteristics & With birth defect $n(\%)$ & Mean IQ (SD)* & Without birth defect $n(\%)$ & Mean IQ (SD)* & $p$-value $\left(\chi^{2}\right.$-test $) \dagger$ \\
\hline \multicolumn{6}{|l|}{ Year of birth } \\
\hline $1967-70$ & $1,386(23.0)$ & $5.12(1.91)$ & $106,519(34.2)$ & $5.14(1.83)$ & \\
\hline $1971-74$ & $1,883(31.3)$ & $5.32(1.92)$ & $98,062(31.4)$ & $5.25(1.85)$ & \\
\hline \multicolumn{6}{|l|}{ Birth order } \\
\hline 1 & 2,964 (49.2) & $5.44(1.84)$ & $128,088(41.1)$ & $5.42(1.81)$ & \\
\hline $2+$ & $3,059(50.8)$ & $5.08(1.88) \S$ & $183,650(58.9)$ & $5.07(1.80) \S$ & $<0.0005$ \\
\hline $20-24$ & $2,130(35.4)$ & $5.11(1.80)$ & $110,765(35.5)$ & $5.09(1.79)$ & \\
\hline $25-29$ & $2,084(34.6)$ & $5.40(1.90)$ & $104,274(33.4)$ & $5.36(1.82)$ & \\
\hline $30-34$ & $957(15.9)$ & $5.45(1.95)$ & 49,498 (15.9) & $5.37(1.83)$ & \\
\hline$>34$ & $412(6.8)$ & $5.34(1.81) \S$ & $24,177(7.8)$ & $5.29(1.85) \S$ & 0.06 \\
\hline \multicolumn{6}{|l|}{ Marital status } \\
\hline Unmarried & $615(10.2)$ & $4.73(1.76)$ & $26,747(8.6)$ & $4.82(1.78)$ & \\
\hline High & $725(12.0)$ & $6.44(1.61) \S$ & $30,994(9.9)$ & $6.36(1.66) \S$ & $<0.0005$ \\
\hline Total & 6023 & $5.26(1.87)$ & 311,738 & $5.22(1.82)$ & \\
\hline
\end{tabular}

* Analysis of variance (overall test of mean intelligence test score by categories of the listed maternal characteristics).

$\dagger \chi^{2}$ test (in a $2 \times X$-table, testing whether proportion of any birth defect distributes differently by each of the listed maternal characteristics).

$\ddagger p=0.005$.

$\S p<0.0005$.

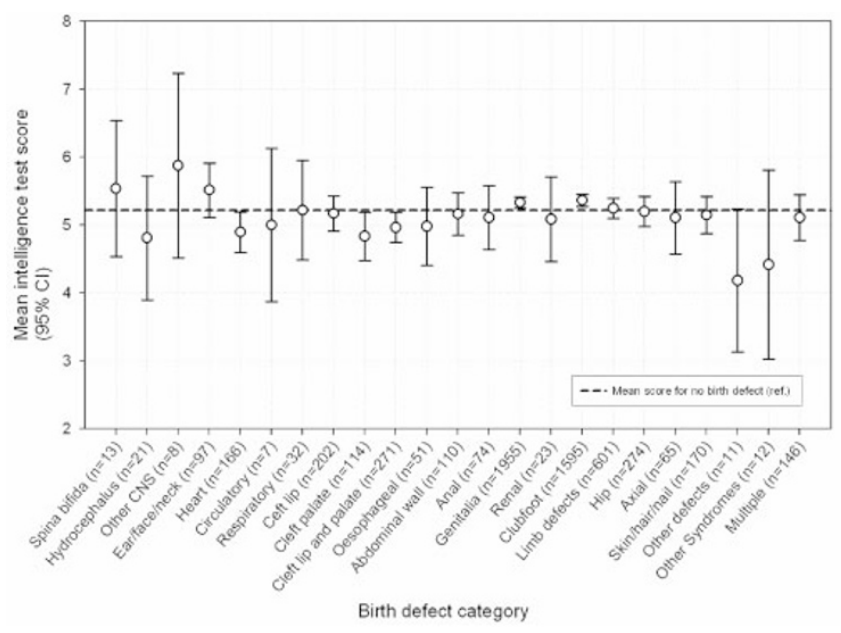

Figure 2. Mean intelligence test score according to category of birth defect (with more than five cases). Except for the multiple category, all categories include one single birth defect diagnosis. 317,761 male infants, Medical Birth Registry of Norway, 1967-1979, linked with the Norwegian Conscripts Service, 1984-1999

cant and of interest to families and health workers concerned about infants with birth defects.

Strengths of this study are the large sample size and the fact that it is population-based. Moreover, linkage of four national registries facilitated nearly complete follow-up information; $94 \%$ of the birth cohort was traced until age $18 \mathrm{y}$. Altogether, $73.8 \%$ of all males born with a birth defect were drafted.

The persistence of mortality and disability risks among those with birth defects probably reflect ongoing complications related to the defects. Accordingly, loss to follow-up is inevitable. A higher proportion (26.2\%) of infants with birth defects never attended the draft board compared with those without defects $(10.4 \%)$. Hence, a selection bias might be possible. This may affect the validity regarding intellectual performance. Not attending the draft board may be associated with lower intellectual performance, implying an overestimation of the mean scores among those with birth defects. Thus, if data on intellectual performance in the non-drafted subgroups had been available, the observed intellectual performance in the birth defect group might have been lower. However, comparisons with mortality and disability figures in follow-up studies on oral clefts (18) and spina bifida (19) indicate that the losses to follow-up for these subgroups are not higher than in other studies. This may also apply to the other subgroups in our study. Moreover, despite loss to follow-up, we observed significantly lower mean scores in subgroups that could be expected to have lower scores according to previous literature; thus supporting our conclusions regarding the defect categories that have hardly been studied previously.

Ascertainment of birth defects was not complete. Of live born males in the present cohort, $2.4 \%$ was affected by malformations. Similar rates have been published in other studies $(20,21)$. Not all birth defects are apparent within the first week of life. For example, clinical manifestations of many heart defects do not occur until after discharge from the maternity institution (4). Thus, the registered heart defects probably represent the most affected infants. However, for neural tube defects and oral clefts, the proportions of cases ascertained by the registry have been estimated at approximately $90 \%$ and $80 \%$, respectively (22). Low ascertainment implies that there may be infants with undiagnosed birth defects in the reference group of unaffected males. Such 
Table 3. Mean intelligence test score with 95\% confidence interval (CI) of conscripts with selected single and multiple birth defects. 317,761 male infants, Medical Birth Registry of Norway, 1967-1979, linked with the National Conscripts Service, 1984-1999

\begin{tabular}{|c|c|c|c|c|}
\hline \multirow[b]{2}{*}{ Birth defect category } & \multirow[b]{2}{*}{$n$} & \multirow[b]{2}{*}{$\begin{array}{l}\text { Mean intelligence } \\
\text { test score }(95 \% \mathrm{CI})\end{array}$} & \multicolumn{2}{|c|}{$p$-values } \\
\hline & & & $\begin{array}{l}\text { Comparing single } \\
\text { with additional } \\
\text { defects } \\
\text { Adjusted* }\end{array}$ & $\begin{array}{c}\text { Comparing single } \\
\text { with no } \\
\text { defect } \\
\text { Adjusted* }\end{array}$ \\
\hline No defect & 311,738 & $5.22(5.21$ to 5.22$)$ & & \\
\hline \multicolumn{5}{|l|}{ Heart } \\
\hline \multicolumn{5}{|l|}{ Cleft palate } \\
\hline Single defect & 114 & $4.83(4.48$ to 5.19$)$ & & 0.045 \\
\hline Additional defect(s) & 11 & $4.82(3.50$ to 5.13$)$ & 0.6 & \\
\hline \multicolumn{5}{|l|}{ Cleft lip } \\
\hline Single defect & 202 & 5.17 (4.91 to 5.43$)$ & & 0.83 \\
\hline Additional defect(s) & 6 & $5.50(3.56$ to 7.44$)$ & 0.07 & \\
\hline Multiple defects total & 146 & $5.11(4.77$ to 5.45$)$ & 0.2 & \\
\hline
\end{tabular}

* Analysis of variance. Adjusted for maternal age (years): $<20,20-24,25-29,30-34,>35$; maternal education (years): $<11,11-14,>14$; marital status: married or unmarried; parity: 0,1+. Reference groups: maternal age, 25-29 years; maternal education, 11-14 years; parity, +1 .

misclassification would tend to deflate the effects of having a birth defect on intellectual performance. For example, misclassification may affect the multiple defects category, i.e., infants with multiple defects may mistakenly have been classified as having a single defect. Our study could not demonstrate any differences in intellectual performance neither when comparing infants with multiple defects with those having a single defect, nor compared with unaffected males. This lack of effects in our data may be due to the biases discussed above. False positive cases may also represent a problem. For example, clubfoot may be diagnosed clinically at birth but be invalidated after discharge. In general, false positive cases will reduce the effect of the diagnosis.

Although we adjusted for maternal educational level, a proxy variable for maternal intelligence and socioeconomic status, residual confounding may still be present. The association between social status and birth defect is unclear (5). In our study the risk for not being drafted for males with birth defects appeared to be highest among offspring of low educated mothers. This finding may reflect differences in life-style factors, intellectual stimulation of offspring, and social conditions, but may also be due to the influence of maternal genes on intellectual and social abilities.

Birth defects that often cause death may also cause more serious morbidity among the survivors (1). In our study, males with birth defects who survived to adulthood had a six-fold increased risk of being disabled, as well as a reduced likelihood of being drafted, compared with unaffected males. The degree of disability varied according to the severity (i.e., mortality) of the defect, reflecting both the medical and social consequences to adult health in the individuals concerned. Unfortunately, detailed information on disability status, for example in terms of dependence on assistance in everyday life, was unavailable.
We evaluated whether birth defect categories with high mortality and high disability were associated with impaired intellectual performance at conscription. The cluster of birth defects associated with low mortality had significantly better intelligence test score than the cluster of defects associated with higher mortality. However, in the separate analyses, men with heart defects or cleft palate were the only subgroups in which intellectual performance was adversely affected. Further, the RRs for both mortality and disability were considerably higher among men with heart defects compared with cleft palate. Thus, for each specific birth defect category, the presence of high mortality and disability in Fig. 1 was not reflected in lower intelligence test scores in Fig. 2.

Our finding of intellectual deficits in males with heart defects is consistent with other studies $(10,23,24)$. An important issue is whether intellectual impairment is a consequence of the type of cardiac condition, the surgical procedures used, or a combination of these. In our study cohort, the heart defects category comprised 141 cases of unspecified blue baby or congenital heart murmurs; in addition, two men had transposition, 17 men had ventricular or atrial septal defect, and six men were recorded as having other specified heart defects such as dextrocardia. Since information on surgical treatment was unavailable in our registries, we could not clarify whether the deficit was due to the cardiac condition or its treatment. Heart defects are more frequent in syndromes associated with intellectual impairment (25). DiGeorge syndrome is often seen in congenital heart disease, and may be associated with intellectual impairment in the absence of other lesions.

Cognitive dysfunction in infants born with cleft lip and/or palate is well acknowledged $(11,26,27)$, and may be related to abnormal brain development alongside facial development. Our data support the finding that intellectual function may be affected among those with cleft palate only. Intelligence test 
score among conscripts having cleft palate as a single defect was not lower than among those having additional defects, but the number in the latter group was low. In contrast, a study by Swanenburg de Veye et al. (26) found that children with additional defects were disadvantaged with respect to their mental development. In that study, one-third of the total sample had additional defects. This is consistent with other reports (28) and clearly higher than in our study. Thus, bias due to misclassification may be present in our study.

In a follow-up study of 117 people with spina bifida, 39 of the 54 survivors had an IQ equal to or more than 80 (19). In a study by Iddon et al., cognitive function was unaffected in patients with spina bifida alone (12). Although not directly comparable, these studies support our finding that intellectual performance was not seriously impaired in spina bifida. The latter study also showed that the majority of test scores was lower in patients with hydrocephalus (with or without spina bifida) (12). In our study, intelligence test score for hydrocephalus (without spina bifida) was low, although not statistically significant, when compared with men without defects.

Birth defects per se include a variety of abnormalities. In the present study, the birth defects were grouped on the basis of the organ involved, according to the ICD-8. The subgroups constitute rather broad categories that may differ from categories based on a common underlying mechanism, implying the possibility of different causal pathways for the different types of birth defects within the same organ group. We performed sub-analyses which departed from the organspecific categories (data not shown). For example, we could not demonstrate any significant difference in intellectual performance among infants born with midline-defects (i.e., neural tube defects without hydrocephalus, oral clefts, gastroschisis, epispadias, and hypospadias) compared with those without such defects. Intellectual impairment has been reported among infants with gastroschisis or omphalocele (29). In our study these defects were combined in the abdominal wall category; however, no significant differences were observed when comparing infants with gastrochisis or omphalocele with those without defects.

Questions can be raised as to whether our findings apply to other countries and the present cases. In Norway, infants with birth defects possibly may benefit especially from the well established social welfare system, with economical, cultural and social support in addition to medical treatment, reducing possible adverse long-term effects of handicaps. Due to time trends in such support and treatment, and hence in survival for the different types of malformations, our results may be influenced by treatment and support that have improved over the years.

With the progress in peri-natal and neonatal medical care, more infants with serious birth defects may survive into adulthood. On the other hand, advances in fetal medicine may result in induced abortion of the most seriously affected fetuses, and consequently only the mild cases may survive. In either situation, research into the long-term outcomes of infants with birth defects is important. Our historical data do not allow us to speculate on ethical issues and quality of life in people born with birth defects. Still, our conclusion is that for the majority of birth defects in the present birth cohort, infants who survived without serious disability did not run a risk of intellectual impairment.

Acknowledgments. We thank John Ivar Brevik and his staff at the Norwegian Conscripts Service for help in collecting the data from the draft examination, Ola Thune for technical assistance, and Grethe S. Tell and David Batty for helpful comments on previous versions of the manuscript.

\section{REFERENCES}

1. Skjærven R, Wilcox AJ, Lie RT 1999 A population-based study of survival and childbearing among female subjects with birth defects and the risk of recurrence in their children. N Engl J Med 340:1057-1062

2. Mitchell LE 1997 Genetic epidemiology of birth defects: nonsyndromic cleft lip and neural tube defects. Epidemiol Rev 19:61-68

3. Melve KK, Skjærven R 2002 Families with birth defects: is birth weight of nonmalformed siblings affected? Am J Epidemiol 155:932-940

4. Lie RT, Wilcox AJ, Skjærven R 2001 Survival and reproduction among males with birth defects and risk of recurrence in their children. JAMA 285:755-760

5. Vrijheid M, Dolk H, Stone D, Abramsky L, Alberman E, Scott JE 2000 Socioeconomic inequalities in risk of congenital anomaly. Arch Dis Child 82:349-352

6. Batty GD, Deary IJ 2004 Early life intelligence and adult health. BMJ 329:585-586

7. Osler M, Batty GD 2004 Commentary: influence of early life intelligence test performance on later health: do lower scoring children become less healthy adults? Int J Epidemiol 33:414-415

8. Kuh D, Richards M, Hardy R, Butterworth S, Wadsworth ME 2004 Childhood cognitive ability and deaths up until middle age: a post-war birth cohort study. Int J Epidemiol 33:408-413

9. Whalley LJ, Deary IJ 2001 Longitudinal cohort study of childhood IQ and survival up to age 76. BMJ 322:819-

10. Griffin KJ, Elkin TD, Smith CJ 2003 Academic outcomes in children with congenital heart disease. Clin Pediatr (Phila) 42:401-409

11. Nopoulos P, Berg S, VanDemark D, Richman L, Canady J, Andreasen NC 2002 Cognitive dysfunction in adult males with non-syndromic clefts of the lip and/or palate. Neuropsychologia 40:2178-2184

12. Iddon JL, Morgan DJ, Loveday C, Sahakian BJ, Pickard JD 2004 Neuropsychological profile of young adults with spina bifida with or without hydrocephalus. J Neurol Neurosurg Psychiatry 75:1112-1118

13. Irgens LM 2000 The Medical Birth Registry of Norway. Epidemiological research and surveillance throughout 30 years. Acta Obstet Gynecol Scand 79:435-439

14. Sundet JM, Barlaug D, Torjussen T 2004 The end of the Flynn Effect? A study of secular trends in mean intelligence test scores of Norwegian conscripts during half a century. Intelligence 32:349-362

15. Eide M, Øyen N, Skjærven R, Nilsen ST, Bjerkedal T, Tell GS 2005 Size at birth and gestational age as predictors of adult height and weight. Epidemiology 16:175-181

16. Sundet JM, Tambs K, Magnus P, Berg K 1988 On the question of secular trends in the heritability of IQ test scores: a study of Norwegian twins. Intelligence 12:47-59

17. Tambs K, Sundet JM, Magnus P, Berg K 1989 Genetic and environmental contributions to the covariance between occupational status, educational attainment, and IQ: a study of twins. Behav Genet 19:209-222

18. Christensen K, Juel K, Herskind AM, Murray JC 2004 Long term follow up study of survival associated with cleft lip and palate at birth. BMJ 328:1405

19. Hunt GM, Oakeshott P 2003 Outcome in people with open spina bifida at age 35: prospective community based cohort study. BMJ 326:1365-1366

20. Basso O, Olsen J, Christensen K 1999 Recurrence risk of congenital anomalies-the impact of paternal, social, and environmental factors: a population-based study in Denmark. Am J Epidemiol 150:598-604

21. Kalter H, Warkany J 1983 Medical progress. Congenital malformations: etiologic factors and their role in prevention (first of two parts). N Engl J Med 308:424-431

22. Lie RT, Heuch I, Irgens LM 1994 Maximum likelihood estimation of the proportion of congenital malformations using double registration systems. Biometrics 50:433-444

23. Wray J, Sensky T 2001 Congenital heart disease and cardiac surgery in childhood: effects on cognitive function and academic ability. Heart 85:687-691

24. Limperopoulos C, Majnemer A, Shevell MI, Rohlicek C, Rosenblatt B, Tchervenkov C, Darwish HZ 2002 Predictors of developmental disabilities after open heart surgery in young children with congenital heart defects. J Pediatr 141:51-58

25. Rimoin D, Connor J, Pyeritz R, Korf B 2002 Emery and Rimoin's Principles and Practice of Medical Genetics. 4th ed. Vol. 1 Churchill Livingstone, London; New York

26. Swanenburg de Veye HF, Beemer FA, Mellenbergh GJ, Wolters WH, Heineman-de Boer JA 2003 An investigation of the relationship between associated congenital malformations and the mental and psychomotor development of children with clefts. Cleft Palate Craniofac J 40:297-303

27. Speltz ML, Endriga MC, Hill S, Maris CL, Jones K, Omnell ML 2000 Cognitive and psychomotor development of infants with orofacial clefts. J Pediatr Psychol 25:185-190

28. Kallen B, Harris J, Robert E 1996 The epidemiology of orofacial clefts. 2. Associated malformations. J Craniofac Genet Dev Biol 16:242-248

29. Berseth CL, Malachowski N, Cohn RB, Sunshine P 1982 Longitudinal growth and late morbidity of survivors of gastroschisis and omphalocele. J Pediatr Gastroenterol Nutr 1:375-379 